\title{
Pleurotus ostreatus inhibits proliferation of human breast and colon cancer cells through p53-dependent as well as p53-independent pathway
}

\author{
ANDREJ JEDINAK $^{1}$ and DANIEL SLIVA ${ }^{1,2,3}$ \\ ${ }^{1}$ Cancer Research Laboratory, Methodist Research Institute; \\ ${ }^{2}$ Department of Medicine and ${ }^{3}$ IU Simon Cancer Center, School of Medicine, \\ Indiana University, Indianapolis, IN, USA
}

Received August 11, 2008; Accepted September 26, 2008

DOI: 10.3892/ijo_00000122

\begin{abstract}
In spite of the global consumption of mushrooms, only two epidemiological studies demonstrated an inverse correlation between mushroom intake and the risk of cancer. Therefore, in the present study we evaluated whether extracts from edible mushrooms Agaricus bisporus (portabella), Flammulina velutipes (enoki), Lentinula edodes (shiitake) and Pleurotus ostreatus (oyster) affect the growth of breast and colon cancer cells. Here, we identified as the most potent, $P$. ostreatus (oyster mushroom) which suppressed proliferation of breast cancer (MCF-7, MDA-MB-231) and colon cancer (HT-29, HCT-116) cells, without affecting proliferation of epithelial mammary MCF-10A and normal colon FHC cells. Flow cytometry revealed that the inhibition of cell proliferation by $P$. ostreatus was associated with the cell cycle arrest at G0/G1 phase in MCF-7 and HT-29 cells. Moreover, $P$. ostreatus induced the expression of the tumor suppressor p53 and cyclin-dependent kinase inhibitor $\mathrm{p} 21^{(\mathrm{CIP} 1 / \mathrm{WAF} 1)}$, whereas inhibited the phosphorylation of retinoblastoma $\mathrm{Rb}$ protein in MCF-7 cells. In addition, $P$. ostreatus also up-regulated expression of p21 and inhibited Rb phosphorylation in HT29 cells, suggesting that that $P$. ostreatus suppresses the proliferation of breast and colon cancer cells via p53dependent as well as p53-independent pathway. In conclusion, our results indicated that the edible oyster mushroom has potential therapeutic/preventive effects on breast and colon cancer.
\end{abstract}

\section{Introduction}

Cancer is a major public health problem in the United States and other developed countries. Currently, one in four deaths

Correspondence to: Dr D. Sliva, Cancer Research Laboratory, Methodist Research Institute, 1800 N. Capitol Ave, E504, Indianapolis, IN 46202, USA

E-mail: dsliva@clarian.org

Key words: mushroom, breast cancer, prostate cancer, cell proliferation in the United States is related to cancer. Breast cancer in women and colon cancer in men and women continue to be the most common fatal cancers (1). Therefore, modifications of diet and lifestyle offer measures for reducing the risk of developing breast and colon cancer. Carcinogenesis is a complex, multistep process that progresses over many years. Since it is exceptionally difficult to cure malignant tumors, cancer prevention may be a more effective strategy to control and ultimately, overcome cancer. A promising and important group of potential cancer preventive agents are those derived from natural products, particularly dietary substances because of their low toxicity and apparent benefit in other chronic diseases (2).

Edible mushrooms are a valuable source of biologically active compounds (3). The use of mushrooms with potential therapeutic properties raises global interest from the scientific and clinical community based on two main reasons. First, mushrooms demonstrate their efficiency against numerous diseases and metabolic disturbances as serious as cancer or degenerative diseases. These therapeutic effects seem to lay multiple complex pharmacological actions on different cellular and molecular targets (4). The most significant medicinal effects of mushrooms and their metabolites that have attracted the attention of the public is their antitumor properties $(5,6)$. The medicinal use of edible mushrooms extracts seems to be a more natural, less expensive approach and in general involves minimal unwanted side effects. Moreover, purified bioactive compounds derived from edible mushrooms might be a potentially important new source of anticancer agents. The oyster mushroom (Pleurotus ostreatus) is one of the widely cultivated edible mushrooms (7). Several properties have been associated with this mushroom, including antitumor (8), hypocholesterolemic, antiatherogenic, and antioxidative activities $(9,10)$. Moreover, it has also been reported that the oyster mushroom can increase the immune activity of animals (11). In addition, it has been shown that crude oyster extract has a cytotoxic effect on PC-3 cells (12) and aqueous polysaccharide extract has anti-proliferative and pro-apoptotic effects on HT-29 cells (13). However, the molecular mechanism(s) responsible for the inhibitory effects and modulation of cell cycle by P. ostreatus on the breast and colon cancer cells has not been fully elucidated. 
In the present study, we examined the effect of edible mushrooms on the proliferation of human breast and colon cancer cells. Based on our results we propose the mechanism by which $P$. ostreatus inhibits growth of breast and colon cancer cells.

\section{Materials and methods}

Materials. Edible mushrooms (Agaricus bisporus, Flammulina velutipes, Lentinula edodes and Pleurotus ostreatus) were purchased from a local market (Meijer) in Indianapolis, USA.

Preparation of methanol extracts. The mushrooms were ground using a food mixer (Osterizer blander, Sunbeach Products Inc., Boca Raton, FL, USA). This smashed biomass $(100 \mathrm{~g})$ was suspended in $400 \mathrm{ml}$ of absolute methanol and incubated for $48 \mathrm{~h}$ at $200 \mathrm{rpm}$ and $37^{\circ} \mathrm{C}$. The suspension was filtered on Whatman No. 3 paper to remove the biomass. This procedure was repeated twice. The supernatant was concentrated in a rotary evaporator at $50^{\circ} \mathrm{C}$ under reduced pressure. The resulting dried biomass was dissolved in sterile distilled water to make stocks $50 \mathrm{mg} / \mathrm{ml}$ and stored at $4^{\circ} \mathrm{C}$.

Cell cultures. Human cell lines (MDA-MB-231, MCF-7, MCF-10A, HCT-116, HT-29 and FHC) were obtained from ATCC (Manassas, VA, USA). The human breast cancer cell lines (MDA-MB-231 and MCF-7) and human colon cancer cell lines (HCT-116 and HT-29) were maintained in Dulbecco's modified Eagle's medium (DMEM) containing penicillin (50 $\mathrm{U} / \mathrm{ml})$, streptomycin $(50 \mathrm{U} / \mathrm{ml})$ and $10 \%$ fetal bovine serum (FBS). The human mammary epithelial cell MCF-10A cells were maintained in DMEM/F12 (Invitrogen, Carlsbad, CA, USA) supplemented with $5 \%$ donor horse serum, $20 \mathrm{ng} / \mathrm{ml}$ EGF (Upstate, Lake Placid, NY, USA), $10 \mu \mathrm{g} / \mathrm{ml}$ insulin (Sigma, St. Louis, MO, USA), $100 \mathrm{ng} / \mathrm{ml}$ cholera toxin (Bioscience, La Jolla, CA, USA), $0.5 \mu \mathrm{g} / \mathrm{ml}$ hydrocortisone (Sigma), $50 \mathrm{U} / \mathrm{ml}$ penicillin and $50 \mathrm{U} / \mathrm{ml}$ streptomycin. The normal human fetal colon cells (FHC) were cultured in a $1: 1$ mixture of Ham's F12 and Dulbecco's modified Eagle's medium's containing $25 \mathrm{mM}$ HEPES (Sigma), $10 \mathrm{ng} / \mathrm{ml}$ cholera toxin (Bioscience, La Jolla, CA, USA), $5 \mu \mathrm{g} / \mathrm{ml}$ insulin (Sigma), $5 \mu \mathrm{g} / \mathrm{ml}$ transferrin (Bioscience), $100 \mathrm{ng} / \mathrm{ml}$ hydrocortisone (Sigma), and supplemented with 10\% FCS. The cultures were maintained at $37^{\circ} \mathrm{C}$ in $5 \% \mathrm{CO}_{2}$ and $95 \%$ humidity.

Cell proliferation assay. The anti-proliferative activity of mushroom extracts was evaluated by the tetrazolium salt method according to the manufacturer's instructions (Promega, Madison, WI, USA). All cell lines were cultured in a 96-well plate and treated at indicated times with mushroom extracts $(0-1.0 \mathrm{mg} / \mathrm{ml})$. At the end of the incubation period, the absorption was determined with a plate reader at $570 \mathrm{~nm}$ as previously described (14).

Morphological examination of cancer cells. Cancer cells were grown in 60-mm tissue culture dish and treated with $P$. ostreatus extract $(0-1.0 \mathrm{mg} / \mathrm{ml})$. Cells were examined under a fluorescent microscope (Olympus, Tokyo, Japan) and pictures were taken using a Magna-Fire digital camera (Optotronics, Goleta, CA, USA) for analysis.

Cell cycle analysis. MCF-7 cells $\left(1 \times 10^{6}\right)$ and HT-29 cells $\left(1 \times 10^{6}\right)$ were seeded and after $24 \mathrm{~h}$ treated with $P$. ostreatus extract $(1.0 \mathrm{mg} / \mathrm{ml})$ for the indicated period $(0-48 \mathrm{~h})$. Cells were harvested by trypsinization, washed with Dulbecco's phosphate-buffered saline, and resuspended in propidium iodide $(50 \mu \mathrm{g} / \mathrm{ml})$. Cell cycle analysis was performed on a FACStarPLUS flow cytometer (Becton-Dickinson, San Jose, CA, USA) as previously described (15).

DNA microarrays. MCF-7 and HT-29 cells were treated for $24 \mathrm{~h}$ with vehicle or $1 \mathrm{mg} / \mathrm{ml}$ of $P$. ostreatus extract and total RNA isolated by RNeasy Mini Kit (Qiagen, Germantown, MD, USA). This RNA was used for the evaluation of expression of cell cycle regulatory genes with Cell Cycle Oligo GEArray according to the manufacturer's protocol (SABiosciences, Frederick, MD, USA). GEArray Expression Analysis Suite Software was used for the data analysis.

Western blot analysis. MCF-7 and HT-29 (1x106) were treated with $P$. ostreatus extract $(0-1.0 \mathrm{mg} / \mathrm{ml})$ for $24 \mathrm{~h}$ and whole cell extracts were prepared as previously described (14). Equal amounts of proteins (15 $\mu \mathrm{g} /$ lane) were separated on $4-12 \%$ or $12 \%$ SDS-PAGE (Invitrogen, Carlsbad, CA, USA) and transferred to a PVDF membrane (Millipore, Bedford, MA, USA). The membrane was incubated with the corresponding primary antibodies diluted 1:1000 in blocking solution, as follows: anti-p21, anti-Rb and anti-pRb (Cell Signaling, Danvers, MA, USA), anti-PCNA and anti-p53 (Santa Cruz Biotechnology, Santa Cruz, CA, USA). The expression of each protein was detected by the ECL Western blotting detection system (Amersham Biosciences, Buckinghamshire, UK).

Densitometric analysis. Western blot autoradiograms were scanned with HP-Scanjet 550c. The optical densities of proteins were quantified and analyzed by the UN-SCAN-IT software (Silk Scientific, Orem, UT, USA).

\section{Results}

P. ostreatus inhibits the proliferation of breast and colon cancer cells. In order to evaluate the effect of edible mushrooms on the growth of breast and colon cancer cells, we prepared methanol extracts from fruiting bodies of Agaricus bisporus, Flammulina velutipes, Lentinula edodes and Pleurotus ostreatus. As seen in Fig. 1, extracts from $A$. bisporus, $F$. velutipes, and $L$. edodes exerted little effect on proliferation, whereas the extract from $P$. ostreatus markedly decreased cell proliferation of MCF-7 as well as HT-29 cells. To investigate whether this effect is specific for cancer cells, we treated breast cancer cells (MDA-MB-231, MCF-7) and colon cancer cells (HCT-116, HT-29) with increasing concentrations of P. ostreatus $(0-1.0 \mathrm{mg} / \mathrm{ml})$ for 24 and $48 \mathrm{~h}$. As seen in Fig. 2A, P. ostreatus suppressed the proliferation of highly-invasive breast cancer MDA-MB-231 cells and poorly-invasive breast cancer MCF-7 cells (Fig. 2B) in dose- and time-dependent manner. However, no significant 
A

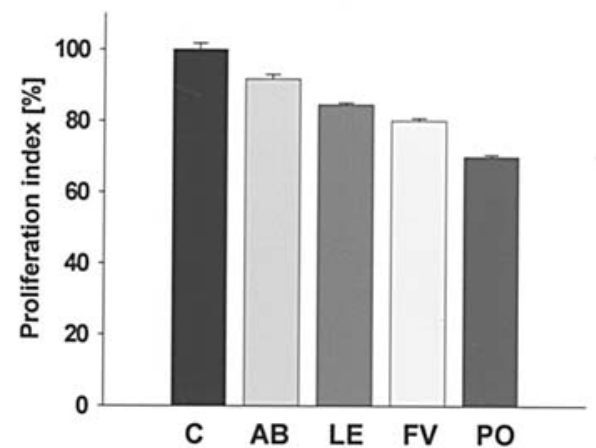

B

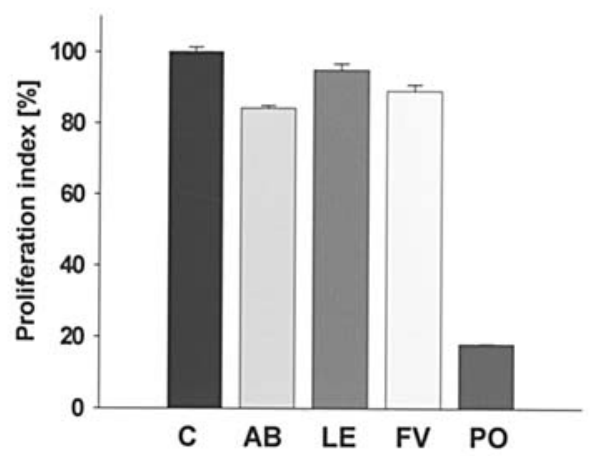

Figure 1. Effects of edible mushrooms on the proliferation of breast cancer and colon cancer cells. (A) MCF-7 and (B) HT-29 cells were treated for 24 h with $1 \mathrm{mg} / \mathrm{ml}$ of mushroom extract and proliferation was assessed as described in Materials and methods. Data are the mean \pm SD of triplicate determinations. C, Control; AB, Agaricus bisporous; LE, Lentinus edodes; FV, Flammulina velutipes and PO, Pleurotus ostreatus.

A

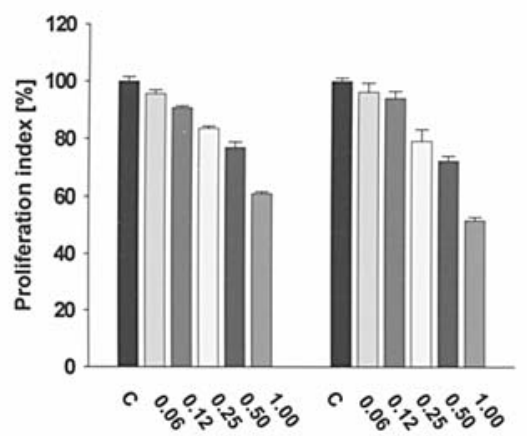

B

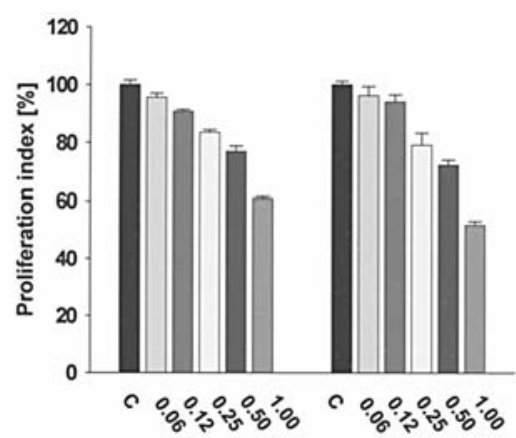

C

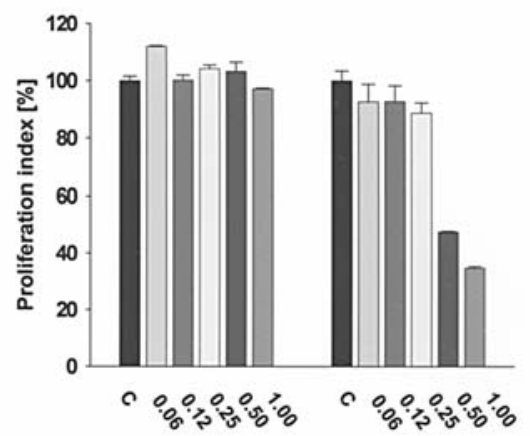

Figure 2. Effects of P. ostreatus on the proliferation of breast cancer and mammary epithelial cells. (A) MDA-MB-231, (B) MCF-7, (C) MCF-10A cells were treated with $P$. ostreatus $(0-1.0 \mathrm{mg} / \mathrm{ml})$ for 24 and $48 \mathrm{~h}$. Proliferation was assessed as described in Materials and methods. Data are the mean \pm SD of triplicate determinations. Similar results were received in at least two additional experiments.

effect on non-tumorigenic breast epithelial cells MCF10A (Fig. 2C) was observed. In addition, P. ostreatus inhibited the proliferation of highly-invasive colon cancer HCT-116 cells (Fig. 3A) and poorly-invasive colon cancer HT-29 cells (Fig. 3B) in a dose- and time-dependent manner. In contrast, proliferation of normal colon cells FHC was not affected by treatment with $P$. ostreatus (Fig. 3C). These results suggest that $P$. ostreatus suppresses proliferation of breast cancer cells and colon cancer cells without significant effect on proliferation of normal human mammary and colon cells.

Effect of P. ostreatus on changes in cell morphology and cell cycle phase distribution. To further investigate the growth modulatory effects of $P$. ostreatus we examined the changes in MCF-7 and HT-29 cell morphology. Typically, MCF-7 cells grow in a flattened, star shape. However, P. ostreatus induced morphological alterations resulting in the elongated shape of MCF-7 cells. Moreover, some of the cells were lifted and also grew in a noticeably more disperse manner (Fig. 4). HT-29 cells grown in a typical goblet-like shape, reflecting propensity for adherence to each other as cells proliferate. P. ostreatus treatment of HT-29 cells changed the cell form to a rounder shape and some cells were lifted from attachment (Fig. 4). In order to investigate the mechanism by which $P$. ostreatus inhibits growth of breast and colon cancer cells, we analyzed cell cycle distribution by flow cytometry. We found that treatment with $P$. ostreatus $(1 \mathrm{mg} / \mathrm{ml})$ caused cell cycle arrest at G0/G1 phase as indicated by the increased amount of MCF-7 and HT-29 cells at G0/G1 from 21\% (0 h) to $60 \%(48 \mathrm{~h}$ ) for MCF-7 (Fig. $5 \mathrm{~A}$ ) and from $26 \%(0 \mathrm{~h})$ to $66 \%$ (48 h) for HT-29, respectively (Fig. 5B).

Effects of P. ostreatus on expression of cell cycle gene expression using cDNA array analysis. To identify genes responsible for the anti-proliferative effects of $P$. ostreatus, we used cDNA microarray analysis. This array profiles the expression of 112 genes key to cell cycle regulation such are cyclins, cyclin-dependent kinase (CDK) inhibitors, CDK phosphates, CDK kinases and genes essential for the DNA damage and mitotic spindle checkpoints. In these experiments, MCF-7 and HT-29 cells were treated with P. ostreatus as described in Materials and methods. As seen in Table I, $P$. ostreatus induced expression of p21, p53, p27, p19 and down-regulated expression of CDK4, CDK6, Ki67, E2F 
A

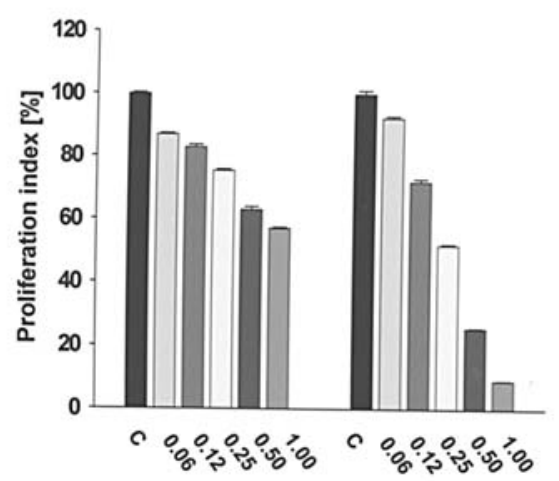

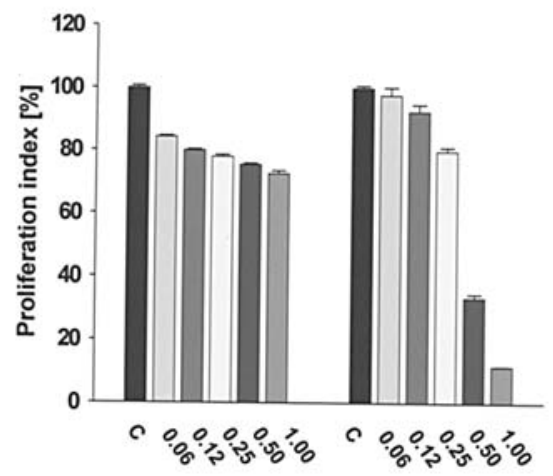

C

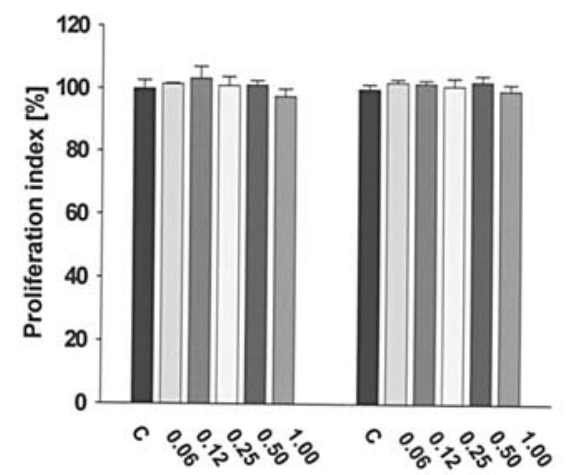

Figure 3. Effects of P. ostreatus on the proliferation of colon cancer and normal colon cells. (A) HCT-116, (B) HT-29, (C) FHC cells were treated with P. ostreatus $(0-1.0 \mathrm{mg} / \mathrm{ml})$ for 24 and $48 \mathrm{~h}$. Proliferation was assessed as described in Materials and methods. Data are the mean \pm SD of triplicate determinations. Similar results were received in at least two additional experiments.

MCF-7
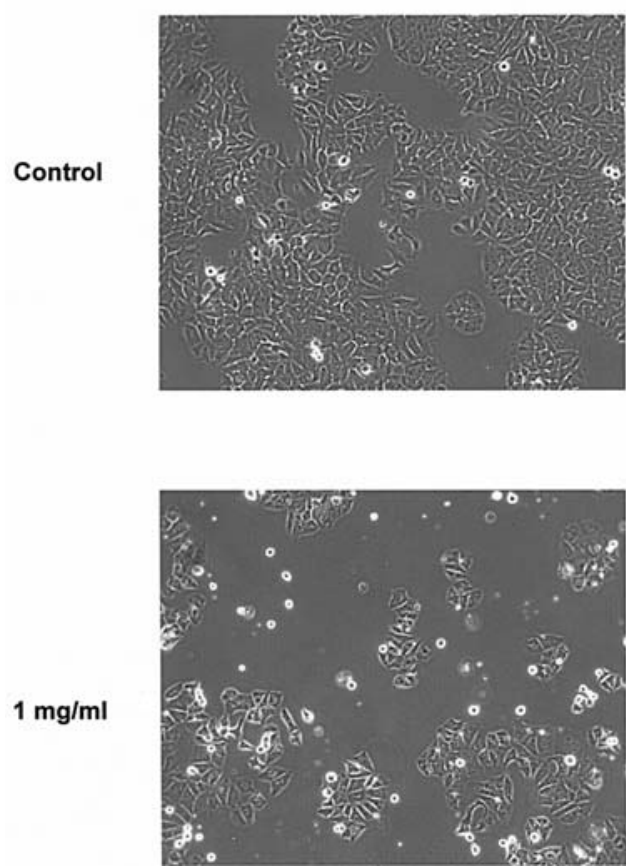

HT-29
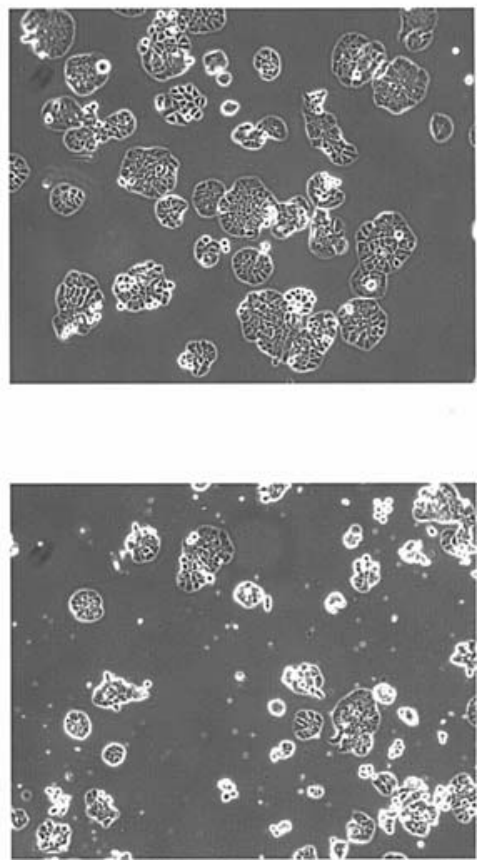

Figure 4. P. ostreatus induces morphological changes in cancer cells. MCF-7 and HT-29 cells were treated with P. ostreatus (0; 1.0 mg/ml) for 48 h and morphological changes evaluated as described in Materials and methods.

transcription factor 1 (E2F1), transcription factor Dp-1 (TFDP1) and proliferating cell nuclear antigen (PCNA) genes in breast cancer MCF-7 cells. Moreover, $P$. ostreatus induced p21, p19, p18, p15 and down-regulated CDK4, Ki-67, E2F1, TFDP1 and PCNA in colon cancer HT-29 cells (Table I).

Effects of P. ostreatus on cell cycle regulatory proteins. Cell cycle arrest at G0/G1 by $P$. ostreatus was recently reported in PC-3 cells (12). However, the molecular mechanism(s) responsible for the inhibition of growth of breast and colon cancer by $P$. ostreatus has not been previously addressed. To confirm our DNA microarray data, whole cell lysates were prepared from MCF-7 and HT-29 cells treated with $P$. ostreatus $(0-1 \mathrm{mg} / \mathrm{ml})$ and subjected to Western blot analysis with $\mathrm{p} 21, \mathrm{p} 53$, PCNA, pRb and Rb antibodies. Thus, $P$. ostreatus significantly up-regulated expression of CDK inhibitor p21 and tumor suppressor p53 in MCF-7 cells (Fig. 6A). Moreover, we identified significant changes in the phosphorylation of retinoblastoma tumor suppressor protein $\mathrm{Rb}$, whose expression and state phos-phorylation play a pivotal role in the control of the G1/S cell cycle checkpoint (16). Expression of proliferating cell nuclear antigen 
Table I. cDNA microarray analysis.

\begin{tabular}{lccccc}
\hline & \multicolumn{2}{c}{ MCF-7 } & & \multicolumn{2}{c}{ HT-29 } \\
\cline { 2 - 3 } \cline { 5 - 6 } & Gene & Fold change & & Gene & Fold change \\
\hline Up-regulated & $\mathrm{p} 53$ & 5.3 & $\mathrm{p} 21$ & 2.1 \\
& $\mathrm{p} 27$ & 1.3 & $\mathrm{p} 19$ & 1.2 \\
& $\mathrm{p} 21$ & 1.5 & $\mathrm{p} 18$ & 1.5 \\
p19 & 1.3 & $\mathrm{p} 15$ & 1.4 \\
& CDK4 & 1.3 & CDK4 & 1.2 \\
CDK6 & 2.2 & TFDP1 & 1.5 \\
& TFDP1 & 1.6 & E2F1 & 5.6 \\
& PCNA & 1.2 & PCNA & 1.7 \\
& Ki67 & 1.5 & Ki67 & 2.0 \\
\hline
\end{tabular}

cDNA microarray was performed and analyzed with Cell Cycle Oligo GEArray and GEAarray Expression Analysis Suite Software as described in Materials and methods.

A

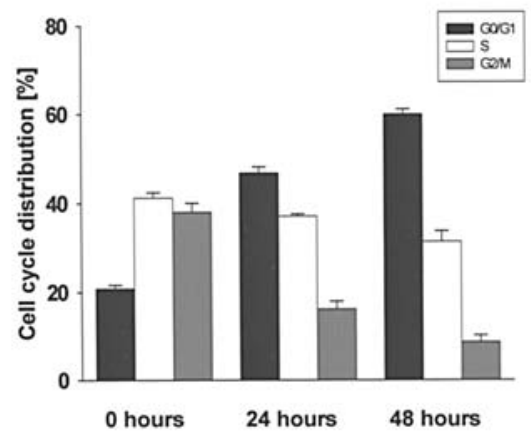

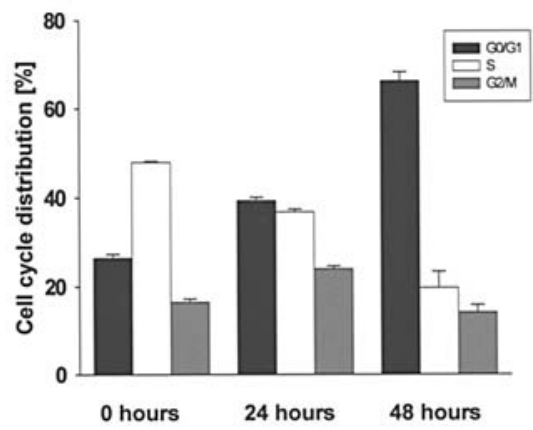

Figure 5. P. ostreatus induces cell cycle arrest at G0/G1 phase. (A) MCF-7, (B) HT-29 cells were treated with P. ostreatus $(1.0 \mathrm{mg} / \mathrm{ml})$ for $0,24 \mathrm{and} 48 \mathrm{~h}$, and cell cycle distribution was evaluated by flow cytometry as described in Materials and methods. Data are the mean \pm SD of triplicate determinations.

A

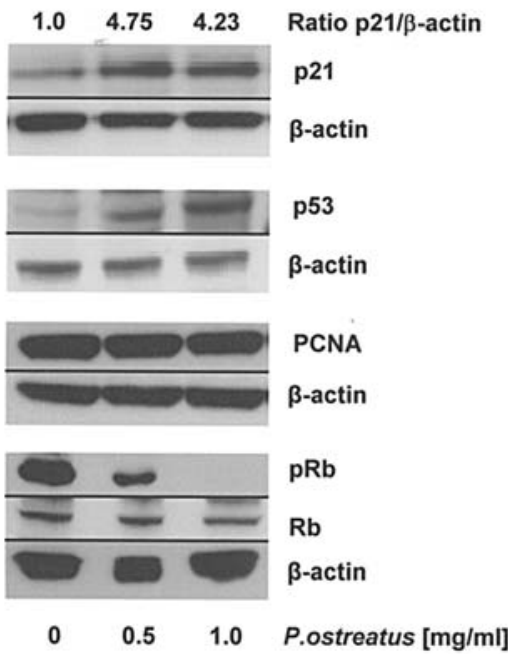

B

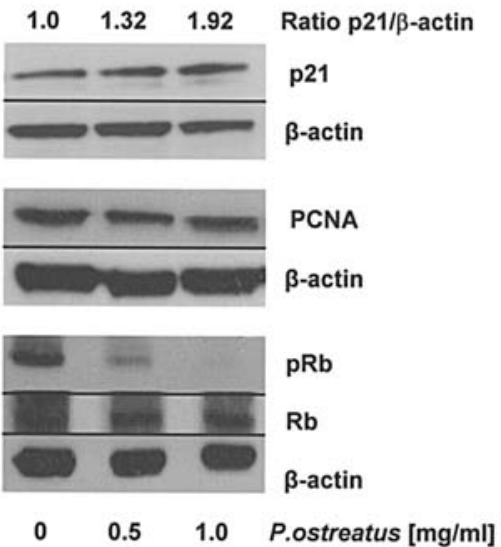

Figure 6. Effects of P. ostreatus on cell cycle regulatory proteins. (A) MCF-7 cells and (B) HT-29 cells were treated with P. ostreatus (0-1.0 mg/ml) for $24 \mathrm{~h}$. The expression of $\mathrm{p} 21, \mathrm{p} 53, \mathrm{PCNA}, \mathrm{Rb}$ and $\mathrm{pRb}$ was evaluated in whole cell extracts by Western blot analysis with the respective antibodies. The equivalent amount of protein was verified by reprobing the blot with anti-ß-actin antibody. The results are representative of three separate experiments. The expression level of p21 (ratio p21/ß-actin) was quantified by densitometry as described in Materials and methods. 


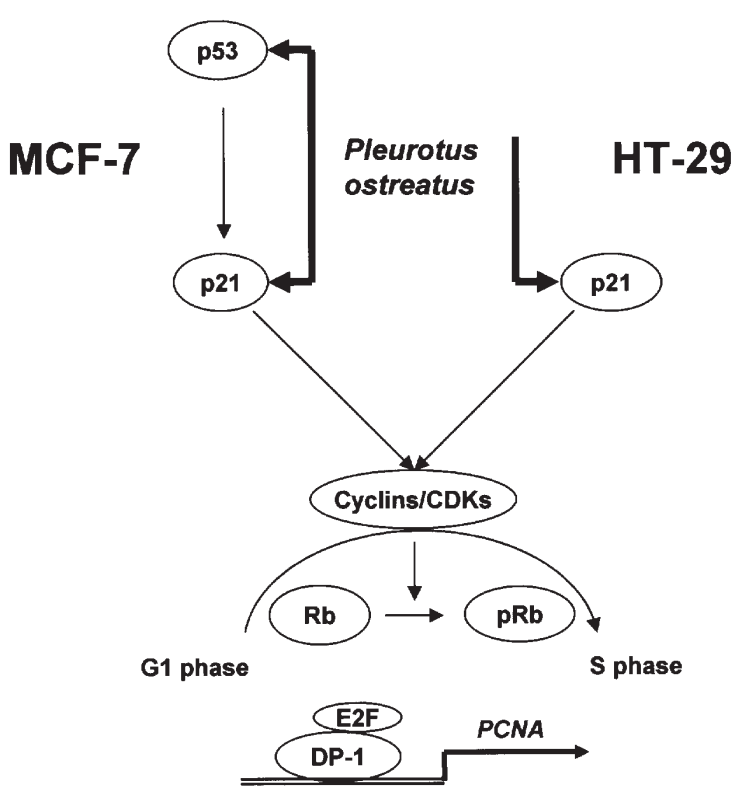

Figure 7. Schematic representation of the expression of cell cycle regulatory genes modulated by P. ostreatus in MCF-7 and HT-29 cells.

(PCNA), a protein involved in cell cycle regulation, DNA synthesis and DNA repair, was only slightly affected by $P$. ostreatus treatment in MCF-7 cells (Fig. 6A). Western blot analysis of HT-29 cell extracts treated with $P$. ostreatus revealed marked up-regulation of expression of $\mathrm{CDK}$ inhibitor $\mathrm{p} 21$. Moreover, $P$. ostreatus significantly inhibited phospho-Rb (pRB) with no effect on the levels of total $\mathrm{Rb}$ in HT-29 cells. However, expression of PCNA in HT-29 treated cells was not affected by P. ostreatus (Fig. 6B).

\section{Discussion}

The number of different mushroom species on earth is estimated at 140,000 of which maybe only $10 \%$ are known. Meanwhile, of those $\sim 14,000$ species currently recorded, $\sim 50 \%$ are considered to possess varying degrees of edibility (17). Oyster mushrooms (Pleurotus species) are edible mushrooms and are widespread throughout the hardwood forests of the world (18). Pleurotus ostreatus is an edible mushroom widely researched for a variety of properties including antitumor effect. However, the molecular mechanism of its action on colon and breast cancer is not fully understood. Here, we demonstrated that $P$. ostreatus induces G0/G1 cell cycle arrest of MCF-7 cells by the up-regulation of the expression of p53 and p21, whereas cell cycle arrest of HT-29 is induced at G0/G1 by the up-regulation of the expression of $\mathrm{p} 21$.

Deregulated cell cycle progression is a common abnormality observed in human cancers. Progression through the cell-division cycle is regulated by the coordinated activities of cyclin/cyclin-dependent kinases (CDK) complexes. One level of regulation of these cyclin-CDK complexes is provided by their binding to CDK inhibitors (CKIs)(19). The CDK inhibitor p21 binds and inhibits the cyclin D-, E-, and A-dependent kinases, regulating $\mathrm{G}_{1}$ to $\mathrm{S}$ phase transition of the cell cycle (20-22). Overexpression of p21 is reported to inhibit the proliferation of mammalian cells (21). In the present study, we observed by using cDNA microarray technology and Western blot analysis that $P$. ostreatus up-regulated expression of p21 and p53 in MCF-7 cells which have wild-type p53. Thus, treatment of MCF-7 cells by $P$. ostreatus may lead to the induction of $\mathrm{p} 21$ by $\mathrm{p} 53$ dependent mechanisms in MCF-7 cells. The increase of p53 protein levels in MCF-7 cells treated with $P$. ostreatus suggests that its growth inhibitory properties may involve the induction of DNA damage response. Moreover, we have found up-regulation of p21 in HT-29 cells at transcription levels and as well as on a protein level. As previously demonstrated, transcription of the p21 gene may be regulated by $\mathrm{p} 53$-dependent as well as p53-independent mechanisms (23). Our data indicated that $P$. ostreatus induces p 21 expression in a dose-dependent manner in HT-29 cells, which lack functional p53, suggesting an independent mechanism. The p53 gene product is known to be a key player in the genotoxic-stress response in mammalian cells by inducing the transcription of $\mathrm{p} 21$, which in turn inhibits the cyclin E/CDK2-dependent phosphorylation of retinoblastoma $(\mathrm{pRb})(24)$. Phosphorylation of $\mathrm{Rb}$ proteins disrupts binding to the E2F proteins, which allows them to act as transcription activators. E2F targets genes that are upregulated as a result of $\mathrm{Rb}$ phosphorylation encode genes necessary for the completion of the G1/S phase transition, as well as genes necessary for DNA replication (25). In the present study, $P$. ostreatus dose dependently decreased the $\mathrm{pRb}$ level, indicating that up-regulation of $\mathrm{p} 21$ by $P$. ostreatus leads to inhibition of CDK activity, which results in decreased phosphorylation of CDK substrates. These results indicate that the decreased $\mathrm{pRb}$ contributes to the $\mathrm{G} 1 / \mathrm{S}$ arrest observed in P. ostreatus treated cells. Moreover, cDNA microarray data showed decreased expression of E2F-1 and TFDP-1, members of the E2F transcription factor family in $P$. ostreatus treated MCF-7 and HT-29 cells, suggesting that the decrease in E2F-1 and TFDP-1 levels may also contribute to cell cycle arrest at the G0/G1 phase. In addition, p21 may also inhibit cell cycle progression via the interaction with proliferating cell nuclear antigen (PCNA) $(26,27)$. PCNA protein is one of the molecules central in determining the life and death of the cell (28). The $\mathrm{C}$ terminus of p21, containing its nuclear localization signal, binds to and inhibits PCNA, thereby blocking DNA replication (29). The present study demonstrated that $P$. ostreatus slightly decreased the protein level of PCNA in MCF-7 treated cells, which may also contribute to the decreased DNA synthesis. However, expression of PCNA in HT-29 treated cells was not affected by $P$. ostreatus.

In conclusion, our data suggest that $P$. ostreatus significantly inhibits proliferation of human breast cancer cells MCF-7 and colon cancer cells HT-29 by G0/G1 cell cycle arrest. Therefore, $P$. ostreatus induces cell cycle arrest of MCF-7 by the up-regulation of the expression of p53 and p21, whereas cell cycle arrest of HT-29 is induced by the upregulation of the expression of p21 (Fig. 7).

In summary, our data demonstrate that the dietary mushroom $P$. ostreatus specifically inhibits growth of colon 
and breast cancer cells without significant effect on normal cells, and has a potential therapeutic/preventive effect on breast and colon cancer.

\section{Acknowledgements}

We thank Kevin Harvey for help with flow cytometry. This study was supported by the Methodist Research Institute and by the Indiana University-Purdue University pilot 2007 grant 'Chemoprevention of colon carcinogenesis by dietary and medicinal mushrooms' to D.S.

\section{References}

1. Jemal A, Siegel R, Ward E, Hao Y, Xu J, Murray T and Thun MJ: Cancer statistics, 2008. CA Cancer J Clin 58: 71-96, 2008.

2. Lim DY, Tyner AL, Park JB, Lee JY, Choi YH and Park JH: Inhibition of colon cancer cell proliferation by the dietary compound conjugated linoleic acid is mediated by the CDK inhibitor p21CIP1/WAF1. J Cell Physiol 205: 107-113, 2005.

3. Rajewska J and Balasinska B: Biologically active compounds of edible mushrooms and their beneficial impact on health. Postepy Hig Med Dosw 58: 352-357, 2004.

4. Poucheret P, Fons F and Rapior S: Biological and pharmacological activity of higher fungi: 20-Year retrospective analysis. Cryptog Mycol 27: 311-333, 2006.

5. Ajith TA and Janardhanan KK: Indian medicinal mushrooms as a source of antioxidant and antitumor agents. J Clin Biochem Nutr 40: 157-162, 2007.

6. Sliva D, Jedinak A, Kawasaki J, Harvey K and Slivova V: Phellinus linteus suppresses growth, angiogenesis and invasive behaviour of breast cancer cells through the inhibition of AKT signalling. Br J Cancer 98: 1348-1356, 2008.

7. Sarangi I, Ghosh D, Bhutia SK, Mallick SK and Maiti TK: Anti-tumor and immunomodulating effects of Pleurotus ostreatus mycelia-derived proteoglycans. Int Immunopharmacol 6: 1287-1297, 2006.

8. Gu YH and Leonard $\mathrm{J}$ : In vitro effects on proliferation, apoptosis and colony inhibition in ER-dependent and ERindependent human breast cancer cells by selected mushroom species. Oncol Rep 15: 417-423, 2006.

9. Bobek $P$ and Galbavy S: Hypocholesterolemic and antiatherogenic effect of oyster mushroom (Pleurotus ostreatus) in rabbits. Nahrung 43: 339-342, 1999.

10. Bobek P, Ozdin L and Kuniak L: Antioxidative effect of oyster mushroom (Pleurotus ostreatus) in hypercholesterolemic rat. Pharmazie 50: 441-442, 1995.

11. Paulik S, Svrcek J, Mojzisova J, Durove A, Benisek Z and Huska M: The immunomodulatory effect of the soluble fungal glucan (Pleurotus ostreatus) on delayed hypersensitivity and phagocytic ability of blood leucocytes in mice. Zentralbl Veterinarmed B 43: 129-135, 1996.
12. Gu YH and Sivam G: Cytotoxic effect of oyster mushroom Pleurotus ostreatus on human androgen-independent prostate cancer PC-3 cells. J Med Food 9: 196-204, 2006

13. Lavi I, Friesem D, Geresh S, Hadar Y and Schwartz B: An aqueous polysaccharide extract from the edible mushroom Pleurotus ostreatus induces anti-proliferative and pro-apoptotic effects on HT-29 colon cancer cells. Cancer Lett 244: 61-70, 2006.

14. Jiang J, Slivova V, Valachovicova T, Harvey K and Sliva D: Ganoderma lucidum inhibits proliferation and induces apoptosis in human prostate cancer cells PC-3. Int J Oncol 24: 1093-1099, 2004

15. Sliva D, Harvey K, Mason R, Lloyd F Jr and English D: Effect of phosphatidic acid on human breast cancer cells exposed to doxorubicin. Cancer Invest 19: 783-790, 2001.

16. Mihara K, Cao XR, Yen A, Chandler S, Driscoll B, Murphree AL, T'Ang A and Fung YK: Cell cycle-dependent regulation of phosphorylation of the human retinoblastoma gene product. Science 246: 1300-1303, 1989

17. Wasser SP. Medicinal mushrooms as a source of antitumor and immunomodulating polysaccharides. Appl Microbiol Biotechnol 60: 258-274, 2002.

18. Jose N, Ajith TA and Janardhanan KK: Methanol extract of the oyster mushroom, Pleurotus florida, inhibits inflammation and platelet aggregation. Phytother Res 18: 43-46, 2004.

19. Besson A, Dowdy SF and Roberts JM: CDK inhibitors: cell cycle regulators and beyond. Dev Cell 14: 159-169, 2008.

20. El-Deiry WS, Tokino T, Velculescu VE, Levy DB, Parsons R, Trent JM, Lin D, Mercer WE, Kinzler KW and Vogelstein B WAF1, a potential mediator of p53 tumor suppression. Cell 75 : 817-825, 1993.

21. Xiong Y, Hannon GJ, Zhang H, Casso D, Kobayashi R and Beach D: p21 is a universal inhibitor of cyclin kinases. Nature 366: 701-704, 1993.

22. Brugarolas J, Chandrasekaran C, Gordon JI, Beach D, Jacks T and Hannon GJ: Radiation-induced cell cycle arrest compromised by $\mathrm{p} 21$ deficiency. Nature 377: 552-557, 1995.

23. Gartel AL and Tyner AL: Transcriptional regulation of the p21((WAF1/CIP1)) gene. Exp Cell Res 246: 280-289, 1999.

24. Weinberg RA: The retinoblastoma protein and cell cycle control. Cell 81: 323-330, 1995.

25. Ohtani K: Implication of transcription factor E2F in regulation of DNA replication. Front Biosci 4: D793-D804, 1999

26. Harper JW, Adami GR, Wei N, Keyomarsi K and Elledge SJ: The $\mathrm{p} 21 \mathrm{Cdk}$-interacting protein Cip1 is a potent inhibitor of G1 cyclin-dependent kinases. Cell 75: 805-816, 1993.

27. Waga S, Hannon GJ, Beach D and Stillman B: The p21 inhibitor of cyclin-dependent kinases controls DNA replication by interaction with PCNA. Nature 369: 574-578, 1994.

28. Paunesku T, Mittal S, Protic M, Oryhon J, Korolev SV, Joachimiak A and Woloschak GE: Proliferating cell nuclear antigen (PCNA): ringmaster of the genome. Int J Radiat Biol 77: 1007-1021, 2001

29. Dotto GP: p21(WAF1/Cip1): more than a break to the cell cycle? Biochim Biophys Acta 1471: M43-M56, 2000. 